\section{Lutando contra a AIDS entre meninas adolescentes: os efeitos da Campanha de Carnaval de 2003 do Ministério da Saúde do Brasil}

\author{
The fight against AIDS among adolescent girls: \\ the impact of the 2003 Carnival campaign \\ by the Brazilian Ministry of Health
}


A campanha de Carnaval incluiu uma mensagem publicitária protagonizada pela cantora Kelly Key e divulgada nas principais emissoras de TV e rádios comerciais do Brasil, além de em cartazes e outdoors. No anúncio veiculado pela TV, a artista entra em uma farmácia e procura um produto nas prateleiras. Dois balconistas notam a sua presença e começam a especular sobre o que ela estaria procurando. Seria creme? Seria batom? Sem demonstrar nenhuma vergonha, Kelly Key se aproxima dos dois e pergunta onde eles colocam as camisinhas, fazendo referência ao fato de que o produto não está visível na farmácia. Os dois homens, surpresos pela pergunta e pela atitude da artista, indicam o local. O objetivo central dessa campanha foi o de estimular as jovens que iniciam a vida sexual a tomarem para si a responsabilidade de prevenção da AIDS, não tendo vergonha de comprar o preservativo ou de carregá-lo na bolsa, exigindo que o parceiro o use.

Campanhas de prevenção da AIDS voltadas para adolescentes são especialmente relevantes quando se consideram os níveis superficiais de conhecimento das causas e das formas de transmissão do HIV nessa faixa etária 1,2,3. Um estudo realizado em diversos países pelo UNICEF (Fundo das Nações Unidas para a Infância) em 2002 revelou que, em média, 50\% dos jovens sexualmente ativos não acreditavam correr o risco de contrair o HIV ou não conseguiam identificar um modo de prevenção da AIDS 4.

É importante também ressaltar a importância da variável gênero no campo da prevenção da AIDS e nas campanhas de comunicação pública. Um relatório divulgado em 2002 pela UNAIDS (Programa Conjunto das Nações Unidas sobre HIV/AIDS) revelou que o grau de desinformação sobre formas de prevenção da AIDS na população entre 15 e 19 anos é maior entre meninas do que entre meninos. No caso brasileiro, $15 \%$ das meninas e $12 \%$ dos meninos não sabiam como se proteger da doença 4 . Além de diferenças em termos de informação sobre a epidemia, adolescentes do sexo feminino têm mais dificuldades para assumir posturas firmes na aquisição e utilização de preservativos. Em uma pesquisa realizada com adolescentes pobres na cidade do Rio de Janeiro, nenhuma das 91 meninas entrevistadas levava consigo preservativos, e só excepcionalmente elas afirmavam que parte da responsabilidade e da iniciativa poderia partir delas 1 . Esses dados sugerem que o poder de negociação de es- tratégias de prevenção da AIDS é bem menor entre meninas, o que torna ainda mais importantes iniciativas como a Campanha de Carnaval 2003, que buscam estimular as jovens a ter uma atitude mais firme na aquisição e no uso de preservativos.

Ao identificar meninas adolescentes como público-alvo e enfrentar desigualdades no campo do gênero e da sexualidade, a Campanha de Carnaval 2003 do MS se destaca em relação a experiências anteriores. Um estudo sobre 317 anúncios de televisão para a prevenção da AIDS em 33 países, incluindo o Brasil, revelou que mulheres tendem a assumir um papel passivo nas campanhas de comunicação pública. Quando personagens femininas aparecem nesses anúncios, elas geralmente assumem uma atitude neutra, sem tomar posições de maneira firme 5. Campanhas tendem, portanto, a refletir normas sociais que limitam o controle das mulheres sobre a sua sexualidade e sobre formas de prevenção da AIDS. A campanha analisada neste artigo constitui uma importante exceção nesse sentido.

O presente texto tem por objetivo avaliar os resultados da Campanha de Carnaval 2003, com base nos dados de uma pesquisa de opinião pública (survey) de âmbito nacional com representantes do público-alvo (adolescentes do sexo feminino). A pesquisa, encomendada e financiada pelo MS, constitui a primeira avaliação sistemática de uma campanha de saúde pública realizada no Brasil. Apesar da sua larga experiência na organização e implementação de campanhas de comunicação pública sobre DST e AIDS 6,7, o Ministério nunca havia realizado uma avaliação sobre os resultados das suas campanhas. Existem estudos qualitativos de recepção de campanhas televisivas de prevenção da AIDS 8 , mas nenhuma pesquisa havia sido desenvolvida para avaliar especificamente os resultados dessas campanhas. Como afirmou Parker 6 há mais de uma década, existe uma urgente necessidade, no caso brasileiro, de dados mais completos que permitam uma avaliação mais sistemática das campanhas de prevenção da AIDS.

\section{As controvérsias em torno da escolha de Kelly Key}

A decisão do MS de escolher a cantora Kelly Key para protagonizar os anúncios da campanha gerou polêmica. No dia 4 de fevereiro de 2003, diversas organizações não governamen- 
tais (ONGs) lançaram um manifesto contra a escolha da artista, solicitando a imediata suspensão da campanha. Sobre a cantora Kelly Key, o manifesto afirmou:

“ $A$ artista que está sendo protagonista dessa nova campanha de carnaval traz, em sua imagem, contradições para nossa luta. São valores que não constroem, nem respeitam uma visão política do mundo e suas relações de gênero. É perversa com as/os jovens quando vende um modelo de sucesso e modo de vida baseada no consumo e na futilidade. A imagem da Kelly Key propõe uma pseudo liberdade sexual, onde o homem é o oprimido e a mulher é a opressora. Acreditamos não ser essa a proposta de homens e mulheres que querem uma sociedade mais equânime e mais respeitosa".

Em resposta, a Coordenação Nacional de DST e AIDS do MS divulgou nota oficial com o título: Escolha de Kelly Key para Campanha de Carnaval foi Baseada em Critérios Técnicos. Nela, a Coordenação afirma que o objetivo da escolha de Kelly Key foi o de "explorar a identificação do público com a cantora, ampliando ao máximo as possíveis representações do adolescente brasileiro". A nota afirma ainda:

"Kelly Key tem 20 anos. Foi casada por seis anos com um homem dez anos mais velho. $E^{\prime}$ mãe de uma menina de dois. Em suas letras, assume-se como mulher vaidosa, dominadora e que sabe o que quer. O sucesso de Kelly Key está no fato de que seu discurso está muito próximo aos anseios da população adolescente feminina brasileira. A escolha de Kelly Key foi embasada em critérios técnicos: a vulnerabilidade da mulher à epidemia da aids está no fato de ela ser subjugada às decisões do homem. Ao mesmo tempo, a adolescente inicia suas relações sexuais com homens mais velhos (em média três anos mais velho) e sem condições de negociação com seu parceiro. O discurso de Kelly Key é a antítese deste comportamento".

A polêmica instaurada pela escolha da cantora Kelly Key para protagonizar a Campanha de Carnaval 2003 revela a importância da decisão sobre quem será a fonte das mensagens de campanhas públicas. Essa escolha é fundamental porque a fonte tem de ter a capacidade de atrair a atenção dos receptores, facilitar a retenção das mensagens e induzir efeitos por causa da sua credibilidade ${ }^{9}$. Entre as fontes mais usadas nesse tipo de campanha, estão as "celebridades", ou seja, artistas ou atletas famosos. Nas campanhas que buscam persuadir a audiência, incluindo aquelas relacionadas à saúde pública, a escolha da fonte que apresentará as mensagens leva em consideração diversos fatores, como a credibilidade e a atratividade da pes- soa 10. Uma das principais generalizações apresentada por uma revisão da literatura sobre campanhas de comunicação na área da saúde é a comprovada capacidade das celebridades de atrair a atenção do público 11 .

Assim, a escolha de Kelly Key levou em conta a necessidade de atingir o público-alvo da Campanha de Carnaval 2003, ou seja, jovens do sexo feminino. O Ministério decidiu escolher uma celebridade com apelo entre esse segmento do público, incluindo credibilidade e atratividade. Além disso, é importante ressaltar que o poder de persuasão de uma fonte cresce quando suas características, como idade e sexo, coincidem com as do público-alvo 5,10.

\section{Modelo para a avaliação de campanhas}

A Campanha de Carnaval 2003 é um exemplo de campanha de comunicação pública, uma ação sem fins lucrativos que visa a informar, persuadir ou motivar mudanças comportamentais em uma audiência numerosa e relativamente bem-definida, através do uso organizado dos meios de comunicação de massa 12. Esse tipo de campanha é extensamente utilizado em todo o mundo, especialmente por agências governamentais da área de saúde interessadas em promover, entre a população, padrões de comportamento que previnam enfermidades ou que protejam a sua saúde. Campanhas de prevenção da AIDS que utilizam os meios de comunicação, em especial a TV, são utilizadas em todos os continentes 5,13,14. Um dos exemplos mais bem-sucedidos é a campanha $S T O P$ AIDS do governo suíço, considerada um fator determinante no aumento de $80 \%$ na venda de preservativos naquele país, nos primeiros cinco anos da campanha 5,15.

Embora o objetivo deste artigo seja avaliar os resultados da Campanha de Carnaval de 2003 do MS, é preciso ressaltar que não existe consenso sobre os critérios que definem uma campanha de comunicação pública como eficiente ou bem-sucedida 16; estes dependem das expectativas e concepções do avaliador. Apesar dessas dificuldades, podemos definir o processo de avaliação como a aplicação sistemática de procedimentos de pesquisa para a compreensão do desenho, implementação e utilidade das intervenções, especialmente no que se refere à eficiência das campanhas de comunicação na consecução dos seus objetivos 17 .

O modelo teórico-conceitual mais utilizado na avaliação de campanhas de comunicação voltadas para a prevenção da AIDS é a pesquisa de opinião sobre conhecimentos, atitudes e 
comportamento, a chamada $K A B$ survey 13,14. Estudos que adotam esse modelo tipicamente investigam os níveis de exposição e compreensão das mensagens das campanhas, bem como relatos sobre atitudes e mudanças comportamentais. Tendo como base esse modelo, podemos identificar as seguintes áreas de avaliação: (a) exposição - verificar que setores da população foram expostos à campanha e/ou se a população-alvo foi exposta às suas mensagens;

(b) compreensão das mensagens - verificar se os receptores dos materiais da campanha, em especial os membros do público-alvo, compreenderam o significado das mensagens;

(c) efeitos da campanha - verificar se a campanha atingiu os efeitos pretendidos.

O campo dos "efeitos" das campanhas de comunicação pública constitui uma das áreas mais difíceis e problemáticas do processo de avaliação. Parte dos motivos que levam avaliadores a considerarem reduzidos ou pouco relevantes os efeitos de diversas campanhas que utilizam os meios de comunicação está em definições bastante rígidas sobre o que constitui um "efeito" e como é possível mensurá-lo. Por esses motivos, uma sugestão importante é ampliar a operacionalização da noção de "efeito" ou "eficiência", para possibilitar um julgamento mais justo e apropriado sobre o sucesso ou fracasso de uma campanha 18.

No caso da Campanha de Carnaval 2003, um dos objetivos centrais foi a adoção de padrões de comportamento mais seguros por adolescentes do sexo feminino de 13 a 19 anos de idade, especialmente o estímulo ao uso de preservativos. Todavia, a pesquisa não busca comprovar se a exposição às mensagens da campanha levou as jovens a alterarem comportamentos, especialmente no que se refere à compra ou utilização de preservativos. Como é bastante difícil comprovar os efeitos das campanhas de comunicação em comportamentos, um número significativo destas enfatiza fatores intermediários que estão associados a mudanças comportamentais. Um exemplo é o papel dessas campanhas na promoção de discussões públicas e privadas sobre a AIDS 13. Discussões interpessoais, com familiares, amigos e outros atores, passaram a ser consideradas importantes na alteração de atitudes e comportamentos 3,13 . Por esse motivo, avaliaremos, neste artigo, o papel da Campanha de Carnaval 2003 no desencadeamento de discussões sobre a prevenção da AIDS no ambiente social das jovens.

Além de efeitos no campo do estímulo à comunicação interpessoal, a pesquisa também propõe verificar em que medida a campanha contribuiu para promover ou reforçar determi- nadas atitudes entre os membros do públicoalvo. Como vimos, um dos objetivos centrais da campanha foi o de estimular as jovens que iniciam a vida sexual a tomarem para si a responsabilidade da prevenção à AIDS, exigindo que o parceiro use o preservativo e não tendo vergonha de comprá-lo ou carregá-lo na bolsa.

A seguir, apresentaremos os procedimentos metodológicos adotados para a avaliação da Campanha de Carnaval 2003, em cada uma dessas áreas, tendo como base os dados de uma pesquisa nacional de opinião pública encomendada pelo MS ao Instituto Ipsos Brasil.

\section{Métodos}

Existe uma variedade de métodos à disposição dos pesquisadores para avaliar os resultados de campanhas de comunicação pública. Experimentos de campo envolvendo mensurações em mais de um momento (por exemplo, antes e depois da campanha) e outras formas de manipulação experimental permitem uma avaliação mais precisa dos vínculos entre causas e efeitos 19. Contudo, métodos observacionais ou quase-experimentais são relativamente caros e exigem mais tempo para a sua realização, sendo contra-indicados para avaliação de campanhas relacionadas a epidemias como a AIDS, que necessitam de respostas mais imediatas 14 .

Na avaliação de campanhas na área da saúde pública que fazem uso dos meios de comunicação, o método mais utilizado é o survey 14,19. O survey interseccional é um método que inclui a coleta de dados em um certo momento, valendo-se de uma amostra de indivíduos que é selecionada para descrever características de uma determinada população 20. Esse tipo de survey se desenvolve a partir da escolha de uma amostra representativa, ou seja, que possui a capacidade de descrever com certa precisão a população total da qual foi selecionada.

Para avaliar os efeitos da Campanha de Carnaval de 2003, o Instituto Ipsos Brasil realizou um survey de âmbito nacional, entre os dias 13 e 17 de março de 2003, com representantes do público-alvo principal da campanha, ou seja, jovens do sexo feminino de 13 a 19 anos de idade. Foram entrevistadas 1.006 jovens em $86 \mathrm{mu}$ nicípios brasileiros de 22 Estados da Federação. Para garantir a representatividade dos dados da pesquisa, foi utilizada uma amostra probabilística por cotas que considerou o tipo (capital, região metropolitana e interior) e o tamanho dos municípios (grande, médio e pequeno porte). A amostra também considerou a classe social das jovens, de acordo com uma classifi- 
cação que leva em conta a renda familiar e o grau de instrução do chefe da família. Definiram-se, assim, cinco categorias de classe social: A (maiores renda e escolaridade), B, C, D e $\mathrm{E}$ (menores renda e escolaridade).

O questionário utilizado no survey incluiu perguntas abertas e fechadas sobre diversos temas, como posição sócio-econômica (renda, escolaridade, idade etc.), hábitos de consumo de mídia, exposição aos materiais da Campanha de Carnaval 2003 e atitudes relacionadas ao uso de preservativos. Os dados foram analisados por meio do programa de computador SPSS.

Dois métodos estatísticos foram utilizados, o qui-quadrado (Tabela 1) e a regressão logística (Tabela 2). No caso da regressão logística, a pesquisa investigou se a exposição às mensagens da Campanha de Carnaval contribuiu para reforçar atitudes relacionadas à afirmação da responsabilidade das mulheres na aquisição de camisinhas. Para investigar essa questão, a seguinte pergunta foi incluída no questionário: "Você acha que comprar camisinha é responsabilidade do homem ou da mulher?", obtendo-se o seguinte resultado: $14 \%$ da jovens responderam que a responsabilidade é dos homens; $2 \%$, que é das mulheres; $84 \%$, que a responsabilidade é de ambos. Todas as respostas nas categorias "ambos" ou "mulher" foram consideradas atitudes favoráveis a uma maior participação da mulher nesta questão. Por esse motivo, foi construída uma variável dummy, na qual foi atribuído o valor “1” (um) para todas as respostas em que se optou pelas alternativas "ambos" e "mulher", e valor "0" (zero) para as respostas em que se optou pela categoria "homem". Foi realizada, então, uma regressão logística, tendo a variável dummy como variável dependen-

Exposição aos anúncios da Campanha de Carnaval 2003, de acordo com região do país e classe social (porcentagens).

\begin{tabular}{|c|c|c|c|c|c|c|c|c|}
\hline & \multirow[t]{2}{*}{ Total no país } & \multicolumn{3}{|c|}{ Por classe social* } & \multicolumn{4}{|c|}{ Por região do país** } \\
\hline & & $A-B$ & C & $D-E$ & Sudeste & Nordeste & Sul & $\begin{array}{c}\text { Norte e } \\
\text { Centro-Oeste }\end{array}$ \\
\hline $\mathrm{Na}$ TV & 81 & 89 & 84 & 74 & 84 & 79 & 71 & 86 \\
\hline No rádio & 25 & 27 & 27 & 23 & 33 & 18 & 24 & 16 \\
\hline Em cartazes & 34 & 39 & 38 & 29 & 35 & 31 & 36 & 41 \\
\hline Em outdoors & 11 & 15 & 14 & 7 & 9 & 14 & 14 & 7 \\
\hline
\end{tabular}

* No que se refere à classe social, as relações são estatisticamente significantes no caso da TV, do outdoor ( $p<0,000)$

e do cartaz ( $p<0,010)$, mas não no caso do rádio (teste qui-quadrado).

** No que se refere às regiões, as relações são estatisticamente significantes no caso do rádio $(p<0,000)$, da TV $(p<0,002)$

e do outdoor $(p<0,050)$, mas não no caso do cartaz (teste qui-quadrado).

Regressão logística das atitudes favoráveis à participação das mulheres na compra de preservativos.

\begin{tabular}{lcc}
\hline & $\begin{array}{c}\text { Modelo } 1 \\
\text { (só Campanha de Carnaval) } \\
\text { Coeficiente B }\end{array}$ & $\begin{array}{c}\text { Modelo 2 } \\
\text { (campanha e outras variáveis) } \\
\text { Coeficiente B }\end{array}$ \\
\hline Exposição à campanha na TV & $0,646^{*}$ & 0,278 \\
Exposição à campanha no rádio & 0,219 & 0,170 \\
Exposição à campanha em cartazes & $-0,376^{\star \star}$ & $-0,442^{\star *}$ \\
Exposição à campanha em outdoors & $1,121^{\star \star *}$ & $0,877^{\star *}$ \\
Idade & & $0,169^{\star \star *}$ \\
Escolaridade & & $0,290^{\star \star *}$ \\
Classe social & 0,020 & $0,378^{*}$ \\
R2 & & 0,077 \\
\hline
\end{tabular}

Níveis de significância: * $p<0,050 ;{ }^{* *} p<0,010 ;{ }^{* * *} p<0,001$. 
te, com o objetivo de verificar o efeito da exposição às mensagens da campanha. Em um segundo modelo, foram introduzidas variáveis sócio-econômicas, tais como idade, escolaridade e classe social, a fim de comparar os efeitos dos materiais da campanha com os efeitos das características individuais das jovens, controlando-os. Foi realizado, ainda, um teste para verificar os níveis de colinearidade das variáveis independentes, não sendo revelados níveis significantes de colinearidade: os valores do fator VIF das quatro variáveis independentes incluídas no modelo 1 variaram de 1.018 a 1.054 ; no caso do modelo 2, os valores do fator VIF das sete variáveis independentes variaram entre 1.031 e 1.545 .

\section{Resultados}

\section{Exposição à Campanha de Carnaval 2003}

A pesquisa investigou o grau de exposição da população-alvo às mensagens da Campanha de Carnaval 2003, veiculadas nos diversos meios de comunicação (cartaz, outdoor, rádio e TV). Que canal atingiu um número maior de jovens? Existem diferenças no grau de exposição às mensagens da campanha nas diversas classes sociais e regiões? Para responder a essas questões, as seguintes perguntas foram introduzidas no questionário:

- Você se lembra de ter visto algum cartaz da campanha do MS com a foto da cantora Kelly Key?

- Você se lembra de ter visto na rua algum outdoor da campanha do MS com a foto da cantora Kelly Key?

- Você se lembra de ter escutado no rádio alguma propaganda da campanha do MS com uma adaptação da música "Baba Baby", da cantora Kelly Key?

- Você se lembra de ter assistido na TV a alguma propaganda da campanha do MS que contou com a participação da cantora Kelly Key?

A Tabela 1 apresenta os resultados. Eles revelam o excelente desempenho dessa campanha de Carnaval, especialmente no caso dos anúncios veiculados na televisão, que foram vistos por $81 \%$ das jovens entrevistadas. A TV se destaca, portanto, como o meio mais eficaz para atingir o público-alvo; todavia, a exposição aos anúncios da TV foi inferior nos setores de menor renda e nas regiões Sul e Nordeste (diferenças estatisticamente significantes). Já as mensagens veiculadas pelas emissoras de rádio atingiram um número bem menor de jovens $(25 \%)$. Entretanto, os anúncios do rádio são os que possuem uma presença mais constante em todas as classes sociais e suas mensagens tiveram altos índices de exposição entre as jovens da região Sudeste. No caso dos anúncios veiculados em outdoors, os índices de recordação são os mais baixos (11\%). Como o número de jovens entrevistadas que viu anúncios em outdoors é muito reduzido (109), a análise apresentada a seguir se concentra nos demais meios de divulgação dos materiais da campanha em estudo (TV, rádio e cartazes).

O resultado mais surpreendente é a abrangência dos anúncios veiculados em cartazes. As mensagens da Campanha de Carnaval 2003 divulgadas por esse meio aparecem em segundo lugar, sendo lembradas por $34 \%$ das entrevistadas. O cartaz é também o canal da mídia que alcança uma distribuição mais uniforme nas regiões, pois, neste caso, as diferenças não são estatisticamente significativas. Entre os locais onde os cartazes foram vistos, destacam-se os postos de saúde (33\%), escolas e faculdades (20\%), farmácias (14\%) e espaços urbanos públicos, como ruas, pontos de ônibus e praças (11\%).

\section{Compreensão das mensagens da campanha}

A pesquisa buscou verificar, também, como as jovens do público-alvo entenderam as mensagens da campanha. Com esse objetivo, perguntas abertas - "O que ficou, o que você entendeu deste anúncio? Quais as mensagens que você lembra?" - foram introduzidas no questionário para verificar como o conteúdo dos anúncios foi compreendido. As respostas a essas questões abertas foram posteriormente agrupadas de acordo com algumas categorias principais.

Considerando-se os três meios de comunicação que atingiram maior exposição - TV, rádio e cartaz -, os dados revelam que a mensagem do anúncio da TV foi entendida, principalmente, como um incentivo para a prevenção da AIDS mediante o uso de preservativos (28\%) e como um incentivo para a compra de preservativo pelas mulheres (24\%). A TV foi, portanto, o meio que se destacou na transmissão de uma das mensagens mais importantes da Campanha de Carnaval 2003, ou seja, a necessidade de que as mulheres não tenham vergonha de adquirir preservativos. $\mathrm{O}$ anúncio da TV foi considerado, também, um incentivo para o uso da camisinha como forma de prevenção da gravidez (24\%), tema que constitui uma das preocupações mais importantes das jovens do público-alvo. Os anúncios veiculados pelo rádio foram entendidos, principalmente, como um incentivo ao uso de preservativos para pre- 
venir gravidez (30\%), AIDS (28\%) e doenças sexualmente transmissíveis (23\%). Já os anúncios veiculados em cartazes foram percebidos pelas jovens, sobretudo, como um incentivo ao uso de preservativos para a prevenção da AIDS (39\%), da gravidez (37\%) e das doenças sexualmente transmissíveis (30\%).

Com base nesses dados, podemos concluir que a mensagem central da campanha, especialmente o incentivo do uso de preservativo como forma de prevenção da AIDS e de doenças sexualmente transmissíveis, foi compreendida pelos membros do público-alvo. É importante acrescentar que a TV foi, mais uma vez, o meio de comunicação mais efetivo em relação a um aspecto muito importante da campanha: a mensagem de que as mulheres devem comprar preservativos (24\%) e que elas não devem ter vergonha disso $(6 \%)$.

A Tabela 3, apresenta os resultados referentes aos três meios de comunicação que atingiram maior exposição.

\section{Efeitos no estímulo a discussões sobre o uso de preservativos}

Qual foi o papel dos anúncios da campanha de Carnaval no agendamento do tema do uso de preservativos entre as jovens do público-alvo? Os anúncios veiculados por quais meios de comunicação geraram mais discussões entre as jovens ou em seu meio ambiente social? Para responder a essas questões, incluíram-se as seguintes perguntas no questionário: "Você se lembra de ter visto alguém comentar este anúncio? (Em caso positivo, quem?)"; "E você? Comentou este anúncio com alguém? (Em caso po- sitivo, com quem?)”. Os resultados revelam que os anúncios da TV se destacaram no desencadeamento de discussões no campo das relações interpessoais das jovens, com $25 \%$ relatando terem visto discussões sobre o anúncio da TV e $27 \%$ relatando terem discutido o anúncio com alguém. Os números para os anúncios de rádio foram $7 \%$ e $8 \%$, respectivamente. Já para os cartazes, $11 \%$ e $13 \%$, respectivamente.

A TV aparece, portanto, como o principal meio no desencadeamento de discussões no dia-a-dia das jovens do público-alvo. Segundo as entrevistadas, as principais pessoas que comentaram o anúncio da TV foram amigos (45\%), colegas da escola (40\%) e parentes $(24 \%)$. No que se refere às pessoas com quem elas conversaram sobre o anúncio da TV, as mais citadas foram amigos (43\%), parentes (33\%) e colegas da escola (30\%).

\section{Efeitos sobre as atitudes referentes à utilização de camisinhas}

Finalmente, a pesquisa investigou se a exposição às mensagens da campanha de Carnaval contribuiu para reforçar atitudes relacionadas à afirmação da responsabilidade das mulheres na aquisição de camisinhas. A Tabela 2 apresenta os resultados da regressão logística das atitudes favoráveis à participação das mulheres na compra de preservativos. No modelo 1 , apresentado na primeira coluna, avalia-se o efeito da exposição às mensagens da campanha nos diversos meios de comunicação. No modelo 2, apresentado na segunda coluna, incluem-se outras variáveis, como classe social, escolaridade e idade.

Respostas espontâneas à pergunta: "O que ficou, o que você entendeu deste anúncio?

Quais as mensagens que você lembra?"*.

\begin{tabular}{lccc}
\hline Itens mencionados (somente os principais) & TV (\%) & Rádio (\%) & Cartaz (\%) \\
\hline Usar camisinha previne a AIDS & 28 & 28 & 39 \\
Usar camisinha previne gravidez & 24 & 30 & 37 \\
Usar camisinha previne DST & 21 & 17 & 30 \\
Usar camisinha evita doenças & 12 & 15 & 23 \\
Sempre se deve usar camisinha & 12 & 3 & 12 \\
Tem que usar camisinha quando for ter relações & 6 & 3 \\
Mulheres não devem ter vergonha de comprar camisinha & 6 & 7 & 0 \\
Mostrar que não é mais criança, que cresceu & 4 & 1 & 1 \\
Incentivar as mulheres a comprarem camisinha & 24 & 23 \\
\hline
\end{tabular}

* A soma das porcentagens de cada meio de comunicação é superior a $100 \%$ porque várias entrevistadas mencionaram mais de um item. 
Os dados sugerem que, quando se considera apenas a exposição às mensagens da campanha de Carnaval (modelo 1), os anúncios divulgados na TV e em outdoors têm um efeito positivo e significativo nas atitudes favoráveis à participação das mulheres na compra de preservativos. Em outras palavras, quanto mais as jovens eram expostas à campanha na TV e em outdoors, mais apoio à responsabilidade da mulher na aquisição de camisinhas elas manifestavam. Os anúncios veiculados no rádio, por sua vez, têm um efeito positivo, contudo este não é estatisticamente significante. A grande surpresa fica por conta do efeito dos anúncios divulgados em cartazes, os quais têm um efeito negativo, e não positivo, na atitude em questão. Ou seja, quanto mais as jovens são expostas aos anúncios dos cartazes, menos definem a compra de preservativos como sendo de responsabilidade das mulheres.

Como explicar esse resultado? Uma possibilidade é a de que os cartazes alcancem um número significativo de jovens e sejam lembrados com freqüência por elas, mas não sejam eficientes para transmitir as mensagens das campanhas. Isto é, ao mesmo tempo em que os cartazes podem ser vistos e lembrados, suas mensagens são ignoradas ou mal compreendidas pelas jovens do público-alvo. Entretanto, esse resultado preliminar deve ser verificado por outras pesquisas, pois os cartazes podem ser efetivos no reforço de outras atitudes, além da responsabilização das mulheres na aquisição de preservativos.

No modelo 2 de regressão logística, apresentado na segunda coluna da Tabela 2, são adicionadas, além das mensagens da campanha de Carnaval, as seguintes variáveis: idade, escolaridade e classe social das entrevistadas. Os resultados revelam que essas variáveis têm um impacto positivo e estatisticamente significativo na responsabilização das mulheres na compra de camisinhas. Quer dizer, quanto maior ou mais alta a idade, o nível de escolaridade e a classe social das entrevistadas, mais elas tendem a afirmar que as mulheres também são responsáveis pela compra de preservativos. Além disso, quando essas variáveis são introduzidas na regressão, os efeitos da exposição aos anúncios de TV da campanha de Carnaval deixam de ser estatisticamente significativos. Ou seja, quando se considera o impacto de outras variáveis, o efeito das mensagens da TV na responsabilização das mulheres na aquisição de preservativos desaparece. Os únicos anúncios da campanha de Carnaval que permanecem estatisticamente significantes no modelo 2 são os veiculados por outdoors (com efeito positivo) e os dos cartazes (com efeito negativo). Assim, após a introdução de alguns controles, apenas as mensagens dos outdoors apresentam um efeito positivo e estatisticamente significante na atitude em questão.

\section{Discussão}

Os resultados do survey realizado para avaliar a Campanha de Carnaval 2003 sugerem que esta atingiu os seus objetivos. Tais resultados comprovam, em primeiro lugar, que as mensagens da campanha atingiram o público-alvo. O grau de exposição aos seus anúncios foi bastante elevado, especialmente no caso da TV (81\% das jovens viram o anúncio da TV). Exposição é apenas uma condição necessária, e não suficiente, para que as campanhas de comunicação pública exerçam um efeito significativo. No entanto, existem evidências importantes sobre a relação entre os níveis de exposição e a magnitude dos efeitos das campanhas. Uma metanálise de publicações sobre 48 campanhas na área da saúde encontrou uma forte e positiva correlação entre os níveis de exposição e os efeitos persuasivos das campanhas 21 . Além disso, os altos níveis de exposição dos anúncios veiculados na TV durante a Campanha de Carnaval 2003 reafirmam os resultados de outros estudos que apontam a TV como a principal fonte de informação dos jovens sobre a AIDS $1,2,3$. Os materiais dessa campanha não só atingiram o público-alvo, como foram muito bem avaliados. O número de jovens que achou os anúncios razoáveis, ruins ou péssimos não passou de $10 \%$, enquanto o número de jovens que gostou muito dos anúncios, com respostas nas categorias excelente e muito bom, esteve entre $44 \%$ e $50 \%$.

Em segundo lugar, é importante ressaltar que as mensagens principais da campanha, especialmente o incentivo ao uso de preservativos como forma de prevenção da AIDS e de DST, foram compreendidas pelas jovens pesquisadas. Além disso, a televisão se destaca na transmissão de uma das mensagens mais importantes da Campanha de Carnaval 2003: a necessidade de que as mulheres não tenham vergonha de adquirir preservativos.

Os resultados da pesquisa de opinião sugerem, ainda, que a campanha teve um importante impacto social. Os anúncios contribuíram para desencadear discussões no meio ambiente social das jovens, principalmente no caso das mensagens transmitidas via TV: um quarto das entrevistadas relatou ter presenciado ou participado de discussões sobre o anún- 
cio da TV. Existem, também, indícios de que os anúncios da campanha contribuíram para reforçar algumas atitudes, especialmente no que se refere à afirmação da responsabilidade das mulheres na aquisição de preservativos, ainda que as evidências nesse campo não sejam conclusivas.

Muitos fatores podem ter contribuído para o relativo sucesso da Campanha de Carnaval 2003. O fato de os anúncios estarem voltados para um público-alvo específico é um deles. Diversos autores argumentam que as campanhas mais efetivas são aquelas que desenvolvem mensagens para públicos específicos, especialmente para os setores com maior risco de con-

\section{Resumo}

Em 2003, o Ministério da Saúde do Brasil (MS) lançou uma campanha nacional para promover o uso de preservativos entre meninas adolescentes. A Campanha de Carnaval 2003 foi transmitida por emissoras de rádio e televisão entre 16 de fevereiro e 3 de março, tendo como público-alvo adolescentes do sexo feminino entre 13 e 19 anos, um grupo social que havia registrado crescimento no número de casos de AIDS e outras doenças sexualmente transmissiveis. O MS contratou a artista Kelly Key para estrelar os anúncios de rádio e TV. Um dos objetivos foi o de estimular as adolescentes a não sentirem vergonha de adquirir preservativos e de exigir que seus parceiros os utilizassem. O artigo apresenta os resultados de um survey nacional encomendado pelo MS, que contou com a participação de 1.006 jovens adolescentes em 86 municípios. Os resultados demonstram que os materiais de campanha alcançaram o público-alvo, e que eles foram muito bem avaliados pelas entrevistadas. Finalmente, os resultados mostram, ainda, que a campanha teve efeitos importantes, como o desencadeamento de discussões no ambiente social das jovens e o reforço de atitudes relacionadas ao uso de preservativos.

Promoção da Saúde; Sindrome de Imunodeficiência Adquirida; Meios de Comunicação de Massa trair o HIV 11,13. Outro fator que pode ter sido importante é o uso integrado de vários meios de comunicação, pois, segundo vários pesquisadores, estratégias integradas de campanha que utilizam diferentes meios de comunicação tendem a ter melhores resultados 9,11.

Não obstante esta ter sido uma campanha que obteve relativo sucesso, os resultados desta primeira avaliação de campanhas de comunicação pública no Brasil precisam ser suplementados por novas pesquisas empíricas. Somente realizando avaliações mais sistemáticas sobre essas importantes iniciativas de prevenção no campo da saúde pública poderemos avançar de forma mais efetiva na luta contra a AIDS.

\section{Agradecimentos}

Uma versão anterior deste texto foi apresentada à 25 a Conferência Anual da International Association for Media and Communication Research, Porto Alegre, 25 a 30 de julho de 2004. Agradeço à Coordenação Nacional de DST e AIDS do Ministério da Saúde pela colaboração no desenvolvimento deste projeto. Sou grato ainda ao parecerista anônimo de Cadernos de Saúde Pública pelas observações críticas. 


\section{Referências}

1. Merchán-Hamann E. Grau de informação, atitudes e representações sobre o risco e a prevenção de AIDS em adolescentes pobres do Rio de Janeiro, Brasil. Cad Saúde Pública 1995; 11:463-78.

2. Hoyos RC, Sierra AV, Martin AH. Fuentes de información y su relación con el grado de conocimientos sobre el SIDA en adolescentes en México. Rev Saúde Pública 1997; 31:351-9.

3. McCombie, Hornik, R, Anarfi, JK. Effects of a mass media campaign to prevent AIDS among young people in Ghana. In: Hornik R, editor. Public health communication. Mahwah: Lawrence Erlbaum Associates; 2002. p. 147-61.

4. Yun H, Govender K, Mody B. Factoring poverty and culture into HIV/AIDS campaigns. Gazette 2001; 63:73-95.

5. Johnson D, Flora J, Rimal RN. HIV/AIDS Public Service Announcements around the world: a descriptive analysis. J Health Comm 1997, 2:223-34.

6. Parker R. The politics of AIDS education in Brazil. In: Daniel H, Parker R, editors. Sexuality, politics and AIDS in Brazil. London: The Falmer Press; 1993. p. 115-28.

7. Lima HMM. Educação e saúde: as campanhas massivas de DST/AIDS do Governo Federal como veículo de produção de sentidos - articulação com a história da epidemia de AIDS no Brasil. J Bras Aids 2002; 3:5-23.

8. Roso A. Ideologia e relações de gênero: um estudo de recepção das propagandas de prevenção da AIDS. Cad Saúde Pública 2000; 16:385-97.

9. Atkin CK. Theory and principles of media health campaigns. In: Rice RE, Atkin, CK, editors. Public communication campaigns. Newbury Park: Sage; 2001. p. 49-68.

10. McGuire WJ. Input and output variables currently promising for constructing persuasive communications. In: Rice RE, Atkin, CK, editors. Public communication campaigns. Newbury Park: Sage; 2001. p. 22-48.

11. Backer T, Rogers E, Sopory P. Designing health communication: What works? London: Sage; 1992.
12. Rice R, Atkin CK. Principles of successful public communication campaigns. In: Bryant J, Zillmann D, editors. Media effects: advances in theory and research. Hillsdale: Lawrence Erlbaum Associates; 1994. p. 365-87.

13. Myhre S, Flora J. HIV/AIDS communication campaigns: progress and prospects. J Health Comm 2000; 5:29-45.

14. Wellings K. Evaluating AIDS public education in Europe: a cross-national comparison. In: Hornik $\mathrm{R}$, editor. Public health communication. Mahwah: Lawrence Erlbaum Associates; 2002. p. 131-46.

15. Swiss AIDS Foundation, Federal Office for Public Health. The STOP AIDS story 1987-1992. Basel: Swiss AIDS Foundation, Federal Office for Public Health; 1993.

16. Salmon CT, Murrray-Johnson L. Communication campaign effectiveness: critical distinctions. In Rice RE, Atkin CK, editors. Public communication campaigns. Newbury Park: Sage Publications; 2001. p. 168-80.

17. Valente TH. Evaluating communication campaigns. In: Rice RE, Atkin, CK, organizadores. Public communication campaigns. Newbury Park: Sage Publications; 2001. p. 105-24.

18. Devine P, Hirt E. Message strategies for information campaigns: a social-psychological analysis. In Salmon CT, editor. Information campaigns. Newbury Park: Sage Publications; 1989. p. 229-58.

19. Lau R, Kane R, Berry S, Ware J, Roy D. Channeling health: a review of the evaluation of televised health campaigns. Health Educ Q 1980; 7:56-89.

20. Babbie E. Métodos de pesquisas de survey. Belo Horizonte: Editora UFMG; 2001.

21. Snyder LB, Hamilton MA. A meta-analysis of U.S. health campaign effects on behavior. In: Hornik R, editor. Public health communication. Mahwah: Lawrence Erlbaum Associations; 2002. p. 357-83.

Recebido em 28/Jul/2004

Versão final reapresentada em 07/Jan/2005

Aprovado em 25/Fev/2005 